\title{
Evaluation of a two-step thermal method for separating organic and elemental carbon for radiocarbon analysis
}

\author{
U. Dusek ${ }^{1,3}$, M. Monaco ${ }^{1}$, M. Prokopiou ${ }^{1}$, F. Gongriep ${ }^{1}$, R. Hitzenberger ${ }^{2}$, H. A. J. Meijer ${ }^{3}$, and T. Röckmann ${ }^{1}$ \\ ${ }^{1}$ Institute for Marine and Atmospheric research Utrecht (IMAU), Utrecht University, Utrecht, the Netherlands \\ ${ }^{2}$ University of Vienna, Faculty of Physics, Boltzmanngasse 5, 1090 Vienna, Austria \\ ${ }^{3}$ Centre for Isotope Research (CIO), Energy and Sustainability Research Institute Groningen (ESRIG), \\ University of Groningen, the Netherlands \\ Correspondence to: U. Dusek (u.dusek@uu.nl)
}

Received: 29 October 2013 - Published in Atmos. Meas. Tech. Discuss.: 14 January 2014

Revised: 7 May 2014 - Accepted: 9 May 2014 - Published: 3 July 2014

\begin{abstract}
We thoroughly characterized a system for thermal separation of organic carbon (OC) and elemental carbon (EC) for subsequent radiocarbon analysis. Different organic compounds as well as ambient aerosol filter samples were introduced into an oven system and combusted to $\mathrm{CO}_{2}$ in pure $\mathrm{O}_{2}$. The main objective was to test which combustion times and temperatures are best suited to separate OC and EC. The final separation step for OC was combustion at $360^{\circ} \mathrm{C}$ for $15 \mathrm{~min}$. Combustion at this temperature proved enough to remove several organic test substances from the filter (including high molecular weight humic acid) but did not remove substantial amounts of EC. For isolation of EC, OC first needs to be completely removed from the filter. This was achieved by water extraction of the filter, followed by combustion of the water insoluble $\mathrm{OC}$ at $360^{\circ} \mathrm{C}$ and combustion at an intermediate temperature step of $2 \mathrm{~min}$ at $450^{\circ} \mathrm{C}$. This last step removed the most refractory OC together with some EC. Finally, the remaining EC was combusted to $\mathrm{CO}_{2}$ at $650^{\circ} \mathrm{C}$. The recovery of black carbon after the intermediate $450^{\circ} \mathrm{C}$ step was approximately $80 \%$. Several tests provided strong evidence that $\mathrm{OC}$ was removed efficiently during the intermediate temperature step: (i) brown carbon, indicative of refractory OC, was removed; (ii) the fraction modern of EC did not decrease significantly if the temperature of the intermediate step was further increased. Based on tests with various organic compounds, we estimated that charred organic carbon could contribute $4-8 \%$ to an elemental carbon sample that was isolated according to our method.
\end{abstract}

\section{Introduction}

Radiocarbon $\left({ }^{14} \mathrm{C}\right)$ measurements allow to distinguish fossil from contemporary carbon sources of carbonaceous aerosol and have therefore become an important method of source apportionment (e.g., Currie, 2000; Szidat et al., 2006, 2007, 2009; Gelencser et al., 2007; Schichtel et al., 2008; Minguillon et al., 2011; El Haddad et al., 2011; Genberg et al., 2011; Gilardoni et al., 2011; Glasius et al., 2011; Dusek et al., 2013). This method exploits the fact that the radioactive carbon isotope ${ }^{14} \mathrm{C}$ is not present in fossil fuels, whereas it is present at a typical contemporary level in carbonaceous material that derives from living biomass. The contemporary ${ }^{14} \mathrm{C}$ level is maintained by the production of ${ }^{14} \mathrm{C}$ from the absorption of thermal neutrons, generated by cosmic ray showers, by $\mathrm{N}_{2}$, mainly in the upper troposphere and stratosphere. The produced ${ }^{14} \mathrm{C}$ is quickly oxidized via $\mathrm{CO}$ to ${ }^{14} \mathrm{CO}_{2}$, which is taken up by the biosphere. Therefore a characteristic ${ }^{14} \mathrm{C} /{ }^{12} \mathrm{C}$ ratio is established for the biosphere, which is closely linked to the atmospheric ${ }^{14} \mathrm{C} /{ }^{12} \mathrm{C}$ ratio (Levin et al., 2010). In organic material that does not exchange $\mathrm{CO}_{2}$ with the atmosphere (e.g., fossil fuel), the ${ }^{14} \mathrm{C}$ isotope decays with the characteristic half-life of 5730 years (Godwin, 1962).

The ${ }^{14} \mathrm{C} /{ }^{12} \mathrm{C}$ ratio of a sample is always reported relative to a standard of oxalic acid, whose activity is related to the activity of the biosphere under natural circumstances in the year 1950 . We report our ${ }^{14} \mathrm{C}$ data as fraction modern $\left(F^{14} \mathrm{C}\right)$, following the nomenclature of Reimer et al. (2004), 


$$
F^{14} \mathrm{C}=\frac{\left.\frac{{ }^{14} \mathrm{C}}{{ }^{12} \mathrm{C}} \text { (sample }\right)}{\frac{{ }^{14} \mathrm{C}}{{ }^{12} \mathrm{C}}(1950)} .
$$

The ${ }^{14} \mathrm{C} /{ }^{12} \mathrm{C}$ ratio of the sample and the standard are both corrected for machine background and normalized for fractionation to $\delta^{13} \mathrm{C}=-25 \%$. The standard is not corrected for decay since the year 1950.

The main sources of carbonaceous aerosol, fossil fuel burning, formation of biogenic secondary organic aerosol (SOA), and biomass burning, have distinct $F^{14} \mathrm{C}$ values. In fossil fuels, which have been buried for much longer periods than the ${ }^{14} \mathrm{C}$ half-life, all ${ }^{14} \mathrm{C}$ has decayed and $F^{14} \mathrm{C}$ is therefore $0 . F^{14} \mathrm{C}$ of the current atmospheric or living biospheric carbon would ideally be around 1 . However, atmospheric ${ }^{14} \mathrm{C}$ levels have been altered by anthropogenic processes, in particular by the nuclear bomb tests in the 1960s and emission of fossil $\mathrm{CO}_{2}$, which does not contain ${ }^{14} \mathrm{C}$. Nuclear bomb testing almost doubled the ${ }^{14} \mathrm{C}$ levels in the atmosphere, but since the stop of the bomb tests $F^{14} \mathrm{C}$ of atmospheric $\mathrm{CO}_{2}$ has decreased steadily and is currently estimated at $F^{14} \mathrm{C} \sim 1.04$ (Levin et al., 2010). As a consequence, primary and secondary particles from biogenic origin have $F^{14} \mathrm{C} \sim 1.04$. Aerosols from wood combustion have a variable $F^{14} \mathrm{C}>1.04$, depending on the age and origin of the wood. Most of the wood burned today was grown over the last 20-60 years, when ${ }^{14} \mathrm{C}$ levels were elevated in the atmosphere, following the nuclear bomb tests. Estimates based on tree growth models (e.g., Lewis et al., 2004; Mohn et al., 2008) give a range from 1.08 to 1.30 for biomass burning aerosols (Szidat et al., 2006, 2007, 2009; Minguillón et al., 2011; El Haddad et al., 2011; Genberg et al., 2011; Gilardoni et al., 2011).

The carbonaceous aerosol is often operationally subdivided in carbon fractions that comprise classes of carbonaceous material with similar properties. One of the most common sub-divisions aims to separate organic carbon from more refractory carbon components that are usually combustion derived and often referred to as soot, elemental, or black carbon. Organic carbon is assumed to consist primarily of individual organic molecules that are not or only weakly light absorbing and cover a great range of volatilities. On the other hand, a universal definition of elemental carbon, black carbon or soot is not agreed on in the literature and what is meant by these terms is often dependent on the analytical method or the context of the research (e.g., Petzold et al., 2013). This ambiguity is mostly caused by the fact that a clear distinction between organic and elemental carbon does not exist, but rather a continuous transition through more and more complex aromatic structures (e.g., Pöschl, 2005; Hammes et al., 2007). These include tars, chars, amorphous-like carbon consisting of randomly oriented poly-aromatic layers (e.g., Gustafsson et al., 2001) and finally carbon nanospheres, which are quite thermally refractory and strongly light absorbing (e.g., Ishiguro et al., 1997). These carbon fractions show gradually lower H/C and $\mathrm{O} / \mathrm{C}$ ratios (e.g., Hammes et al., 2007), higher thermal refractivity and generally increasing light absorption. Petzold et al. (2013) suggest the use of the term "EC", with respect to the refractory component determined by thermal(-optical) methods.

Despite a lack of a clear separation between these fractions, the division into refractory and organic carbon is still useful for source apportionment. The thermally refractory carbon in aerosols is more likely to be combustion derived, even if some of the less refractory parts of the EC continuum, such as chars, are included. If the separation is pragmatically set at a point in the EC continuum that includes only refractory combustion derived carbon into EC, performing ${ }^{14} \mathrm{C}$ analysis on EC and OC separately can help distinguish biomass burning and fossil fuel sources of aerosol carbon. Since EC does not contain any secondary carbon, which usually has a strong contribution from modern sources, EC usually has a lower $F^{14} \mathrm{C}$ than $\mathrm{OC}$ in most ambient samples.

The main challenge remains to isolate combustion-derived $\mathrm{EC}$ as completely as possible from organic material for ${ }^{14} \mathrm{C}$ analysis. The most common solutions for isolating EC (e.g., Szidat et al., 2004; Zhang et al., 2012; Bernardoni et al., 2013) are based on the thermal method by Cachier et al. (1989). In these methods, organic material is volatilized and oxidized to $\mathrm{CO}_{2}$ during a low temperature step (S1) in pure oxygen. Then one or more intermediate steps, possibly in different atmospheres, are used to remove the most refractory OC together with the less refractory part of the EC continuum. In this work we used one intermediate step in pure oxygen (S2) and finally, a high temperature step (S3) in pure oxygen is used to oxidize the most refractory carbon to $\mathrm{CO}_{2}$. The $\mathrm{CO}_{2}$ isolated in step $\mathrm{S} 1$ is assumed to be representative of organic carbon (OC). The remaining material burnt in step $\mathrm{S} 3$ will be called "refractory elemental carbon" $\left(\mathrm{EC}_{\mathrm{r}}\right)$ in this work.

In practice there are several artifacts that can lead to incomplete separation of OC and EC: (1) refractory organic material remaining after S1 and S2, for example biological particles; (2) charring and pyrolysis of organic compounds during S1 and S2, which produce material that is inseparable from the elemental carbon that was contained in the particles originally; (3) premature loss of refractory carbon during steps S1 and S2 through catalytic reactions. The first two mechanisms transfer organic material into the extracted refractory carbon, and therefore usually bias $F^{14} \mathrm{C}_{\left(\mathrm{EC}_{\mathrm{r}}\right)}$ towards high values. Premature loss of EC results in a lower yield of EC, which might make ${ }^{14} \mathrm{C}$ analysis difficult. Since soot from burning biomass seems to be slightly less refractory than soot from fossil fuel burning, it is more easily lost in step S2, which will affect the source apportionment of EC (e.g., Han et al., 2007; Song et al., 2012; Zhang et al., 2012).

The goal of this research is to thoroughly evaluate a separation method for OC and EC based on the THEODORE 
method that was first proposed by Szidat et al. (2004). Our method was developed roughly in parallel with two other recently published methods (Zhang et al., 2012; Bernardoni et al., 2013) and used to analyze a large set of aerosol filter samples collected in the Netherlands. The evaluation of the current method will be also be compared to these two other methodological studies.

\section{Materials and methods}

\subsection{System description}

The system used for thermal separation of OC and EC at IMAU is shown in Fig. 1. It can be divided into two subsystems: (1) the extraction line, where the combustion of the aerosol samples and the $\mathrm{CO}_{2}$ formation occurs and (2) the $\mathrm{CO}_{2}$ purification line, where the carbon dioxide is collected, purified and stored. These two parts are separated by a needle valve (D) that regulates the flow through the reaction tube (usually $30-50 \mathrm{~mL} \mathrm{~min}^{-1}$ ). The needle valve keeps the pressure in the extraction line high, at roughly 1150 mbar, whereas the pressure in the second part is kept below 20 mbar, in order to prevent condensation of $\mathrm{O}_{2}$ in the cryogenic traps.

The first part of the system, the reaction tube, is made from quartz glass and surrounded by three ovens $(C)$. The tube can be opened and a movable sample holder can be inserted. This filter holder can be moved either into the first or the second oven. The first oven is kept at a temperature below $400{ }^{\circ} \mathrm{C}$ and used for OC combustion. The second oven is for $\mathrm{EC}$ combustion. In the third oven, remaining incomplete combustion products are oxidized to $\mathrm{CO}_{2}$ over a platinum catalyst at $650{ }^{\circ} \mathrm{C}$.

The reaction tube is connected to two gas lines that provide pure helium $(\mathrm{He})$ or oxygen $\left(\mathrm{O}_{2}\right)$. The first is an inactive gas used to clean the system before sample extraction, whereas $\mathrm{O}_{2}$ is introduced for the combustion reaction and $\mathrm{CO}_{2}$ formation. Before reaching the reaction tube, these gases are purified. For flushing of the extraction tube these gases can be directed by valve $\mathrm{E}$ directly to the vacuum pump. In this setting of valve $\mathrm{E}$ the $\mathrm{CO}_{2}$ purification line is disconnected from the extraction line.

For collection of a $\mathrm{CO}_{2}$ sample, valve $\mathrm{E}$ is switched and the gases are directed via valve $F$ to the first cryogenic trap (1) and further via valve $G$ to the glass line and vacuum pump. The cryogenic trap is cooled with liquid nitrogen and $\mathrm{CO}_{2}$ and other gases with sufficiently low vapor pressure are collected, whereas $\mathrm{O}_{2}$ and gases with higher vapor pressures are pumped away. At the end of the collection process, valve $\mathrm{E}$ is switched to disconnect the purification line from the extraction line and trap 1 is warmed to release the collected $\mathrm{CO}_{2}$. By switching valve $\mathrm{F}$ the released $\mathrm{CO}_{2}$ is flushed with $\mathrm{He}$ through the $\mathrm{Cu}$ reduction oven to remove traces of $\mathrm{NO}_{\mathrm{x}}$. The water trap after the reduction oven is cooled to

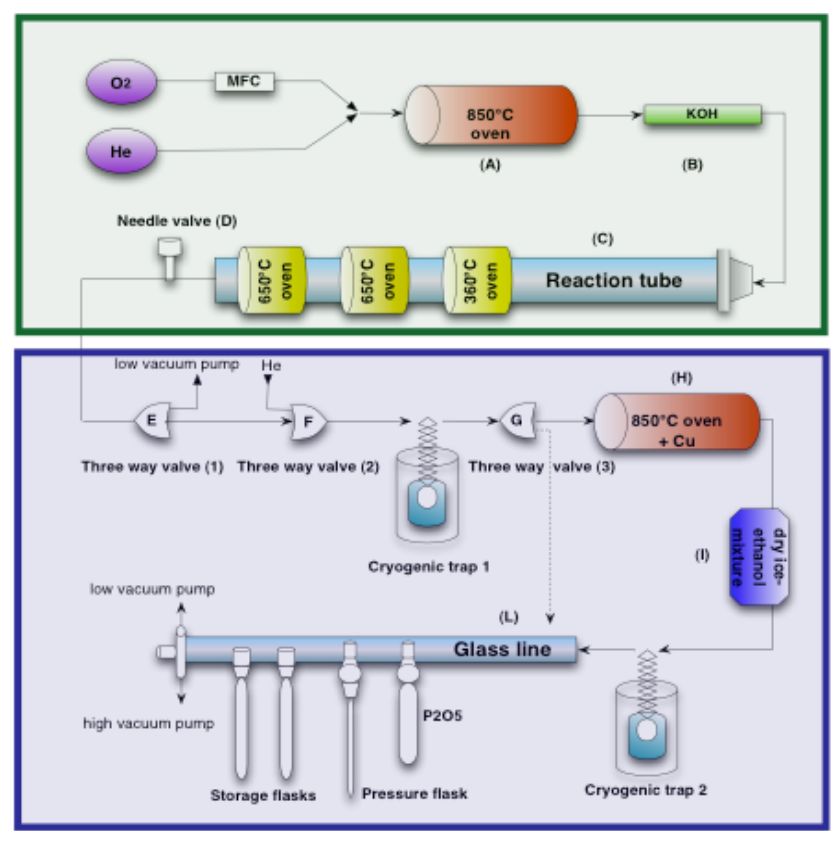

Figure 1. The EC-OC separation system consists of two subsystems: (1) the extraction tube (green box), where organic and elemental carbon are oxidized to $\mathrm{CO}_{2}$ and (2) the purification line (blue box), where $\mathrm{CO}_{2}$ is collected and separated from interfering gases. By switching three-way valve $\mathrm{E}$ to the low vacuum pump the purification line can be separated from the extraction tube.

$-70{ }^{\circ} \mathrm{C}$ using a dry ice-ethanol mixture. The $\mathrm{CO}_{2}$ is collected in cryogenic trap 2. After closing of valve $\mathrm{F}$ and evacuation of the purification line, the $\mathrm{CO}_{2}$ can be released from this trap into the glass line. The glass line consists of different components: a flask containing phosphorous pentoxide $\left(\mathrm{P}_{2} \mathrm{O}_{5}\right)$ to remove any remaining traces of $\mathrm{H}_{2} \mathrm{O}$ vapor, a calibrated volume with pressure sensor for a manometric determination of the amount of $\mathrm{CO}_{2}$, and sample tubes, where the $\mathrm{CO}_{2}$ is stored until the ${ }^{14} \mathrm{C}$ analysis.

\subsection{Measurement protocol}

Before an experiment is started, a sample is inserted into a movable filter holder and placed in the reaction tube. After flushing with $\mathrm{He}$ and $\mathrm{O}_{2}$ the sample is introduced into one of the ovens. For total carbon (TC) combustion the filter piece is directly inserted into oven 2 and heated to $650{ }^{\circ} \mathrm{C}$ for $15 \mathrm{~min}$. The organic carbon (OC) combustion is done in oven 1, usually at $340{ }^{\circ} \mathrm{C}$ or $360^{\circ} \mathrm{C}$ for $15 \mathrm{~min}$, but a range of possible parameters is evaluated in this work. After this step, EC is isolated. The protocol for the EC isolation is the main focus of this work and will be discussed in detail in Sect. 3 .

\subsection{Preparation of test filters}

We performed experiments using known chemical substances to evaluate various aspects of the $\mathrm{OC}$ and $\mathrm{EC}$ 
separation. We used organic compounds and mixtures that represent typical components of the ambient organic aerosol: Glucose (alpha-D-Glucose, anhydrous, $96 \%$, Aldrich), Humic acid (Aldrich), a hydrocarbon standard mix (AccuStandard DRH-002S-R1), a fatty acid methyl ester (FAME) mix (Suppelco47885-U), and a non-volatile organic acid standard mix (Suppelco 46985-U). These organic compounds were applied to pre-heated quartz fiber filters of the same type that is used for collection of ambient aerosol samples. Small amounts $(50-500 \mu \mathrm{L})$ of the three liquid organic mixes were directly pipetted onto the filter. The filters were analyzed after a short drying to evaporate the solvent (chloroform). Glucose was applied as an aqueous solution $(50-100 \mu \mathrm{L})$ and the filter was dried before analysis over silica gel for several hours. In some experiments a commercial carbon black (Elftex 125, Cabot Corporation) was used as a surrogate for EC. The carbon black was pre-heated to $650^{\circ} \mathrm{C}$ in air (not $\mathrm{O}_{2}$ ) for $2 \mathrm{~h}$ to remove adsorbed organic material and a suspension of $0.2 \mathrm{~g}$ of carbon black in $100 \mathrm{~mL}$ of a $20: 80 \%$ ethanol - deionized water mixture was prepared. $200 \mathrm{~mL}$ of this suspension was applied to the filters, which were then dried over silica gel for $24 \mathrm{~h}$.

\section{$2.4{ }^{14} \mathrm{C}$ measurements}

The $\mathrm{CO}_{2}$ collected from the combustion of various aerosol fractions was sent to the Centre for Isotope Research (CIO) at the University of Groningen for graphitization and Accelerator Mass Spectrometer (AMS) measurement. There $\mathrm{CO}_{2}$ was reduced to graphite on a porous iron pellet (de Rooij et al., 2010) at a temperature of $600^{\circ} \mathrm{C}$ in the presence of hydrogen gas at a molecular ratio of $\mathrm{H}_{2} / \mathrm{CO}_{2}$ of 2.5 . The water vapor formed during the reaction was cryogenically removed using Peltier cooling elements. The graphitization yield is usually virtually $100 \%$ for samples larger than $30 \mu \mathrm{g}$. The iron pellet was pressed into a $1.5 \mathrm{~mm}$ target holder, which was introduced into the AMS system for subsequent measurement.

The high-throughput AMS system (van der Plicht et al., 2000) is dedicated to ${ }^{14} \mathrm{C}$ analysis, and measures simultaneously ${ }^{13} \mathrm{C} /{ }^{12} \mathrm{C}$ and ${ }^{14} \mathrm{C} /{ }^{12} \mathrm{C}$ ratios. Sample batches are usually analyzed together with varying amounts of reference materials ranging from 50-500 $\mu \mathrm{g} \mathrm{C}$. Two reference materials with known ${ }^{14} \mathrm{C}$ content are used: the HOxII standard $\left(F^{14} \mathrm{C}=1.3406\right)$ and graphite derived from a ${ }^{14} \mathrm{C}$ free $\mathrm{CO}_{2}$ gas $\left(F^{14} \mathrm{C}=0\right)$. Contamination during the graphitization and AMS measurement causes deviations of the measured $F^{14}$ Cvalues from the nominal values. The magnitude of these deviations can be used to quantify the contamination with modern $\left(F^{14} \mathrm{C}=1\right)$ and fossil carbon $\left(F^{14} \mathrm{C}=0\right)$, which in turn are used for correcting the sample values (de Rooi et al., 2010). The modern carbon contamination is between 0.15 and $0.35 \mu \mathrm{g} \mathrm{C}$, and the fossil carbon contamination is typically around $1 \mu \mathrm{g} \mathrm{C}$ (Prokopiou, 2010).

\subsection{Filter handling}

Ambient aerosol samples were also used as test filters. Three filter samples (CA2, CA12, and CA18) were used as test filters for EC recovery. They ware collected at the Cabauw observatory, a regional field site in the Netherlands in the following time periods: Filter CA2 - 11 to 14 February 2011; Filter CA12 - 27 February to 1 March 2011; Filter CA18 6 to 12 April 2011. Other samples were used to evaluate the final combustion procedure and are more closely described in Table 1. All ambient samples are collected on Whatman quartz fiber filters (QMA 1851-150) using a high volume sampler (Digitel, DHA-80). Before loading, the filters were pre-heated at $800^{\circ} \mathrm{C}$ for several hours, then wrapped in preheated $\left(500^{\circ} \mathrm{C}\right)$ aluminum foil and stored in sealed polyethylene bags at $-18^{\circ} \mathrm{C}$ until use. Then the filters were placed into the high volume sampler in a filter holder that was precleaned with ethanol. After sampling the filter was removed from the sampler immediately, wrapped again in clean aluminum foil and stored at $-18^{\circ} \mathrm{C}$ in a sealed plastic bag until analysis. During the transport to and from the field site (approximately $1 \mathrm{~h}$ ) the filters were kept at ambient temperature. Blank filters used to determine the contamination introduced during handling and storage were treated exactly like the sample filters, except that they were kept in the high volume sampler for one minute only without switching on the sampler.

For analysis circular pieces with a diameter of $3 \mathrm{~cm}$ were cut from the filter. The tweezers and cutter were cleaned in acetone followed by ethanol and let dry for at least $10 \mathrm{~min}$ before handling the filters. For the separation of refractory carbon the water-soluble carbon was removed from the filter pieces by soaking the pieces in MilliQ water overnight $(14 \mathrm{~mL}$ of water per filter piece) and drying them for $24 \mathrm{~h}$ over silica gel. A small fraction of insoluble aerosol material can be lost during the water extraction but this should have little influence on the ${ }^{14} \mathrm{C}$ content of the refractory carbon. However, it is recommended that the loss of insoluble material is monitored e.g., by measuring the absorption before and after water extraction, so that losses can be corrected if necessary.

\section{Tests of the OC-EC separation method}

\subsection{Contamination from filter handling and thermal separation}

\subsubsection{Test procedure}

Since organic material is ubiquitously present in the environment, it is virtually impossible to measure small carbon samples without introducing contamination. If the quartz fiber filters on which the aerosols are sampled or the filter holder are exposed to ambient air they quickly adsorb volatile organic carbon. Any contact with tools or surfaces increases 
the contamination despite pre-cleaning. Therefore, the contamination that cannot be eliminated by our filter handling protocol has to be quantified as accurately as possible and subtracted from the carbon concentration of our samples.

We assessed the contamination introduced by the thermal separation system in two ways. The first way is to directly introduce a pre-cleaned filter piece $\left(7.07 \mathrm{~cm}^{2}\right)$ into the analytical system and measure the amount of $\mathrm{CO}_{2}$ after all the extraction steps detailed in Sects. 2.1 and 2.2. A second, indirect way of inferring the contamination is by combusting standard materials with known ${ }^{14} \mathrm{C}$ content and measuring the deviation from the expected values. Two standard materials (see Sect. 2.4) a HOxII standard and a ${ }^{14} \mathrm{C}$ free graphite powder were put directly onto the sample holder and combusted at $650^{\circ} \mathrm{C}$ for $15 \mathrm{~min}$. Figure 2 shows that $F^{14} \mathrm{C}$ measured on anthracite samples deviates from the nominal value of 0 because of contamination during the extraction. Since the contamination adds a roughly constant amount of $\mathrm{C}$ to each extraction, the experimentally determined $F^{14} \mathrm{C}$ of small amounts of standard material deviates more strongly from the nominal value than for larger amounts. The actual contamination can be parameterized as a sum of two components: a modern contamination $\left(M_{\mathrm{mc}}\right)$ with $F^{14} \mathrm{C}_{(\mathrm{mc})}=1$ and a fossil contamination $\left(M_{\mathrm{fc}}\right)$ with $F^{14} \mathrm{C}_{(\mathrm{fc})}=0$. Then the experimentally determined mass $\left(M_{\mathrm{m}}\right)$ after subjecting the standard material to combustion and purification can be written as follows:

$M_{\mathrm{m}}=M_{\mathrm{st}}+M_{\mathrm{mc}}+M_{\mathrm{fc}}$,

where $M_{\text {st }}$ is the carbon mass of the standard that was introduced into the ovens. This parameterization has a physical foundation, since contamination with aged, partially decayed ${ }^{14} \mathrm{C}$ sources is rare in a laboratory environment and most sources of contamination are either modern carbon or fossil fuel derived. From the $F^{14} \mathrm{C}$ values measured in small standard samples we can calculate the mass of modern contamination by a simple mass balance equation:

$$
\begin{aligned}
M_{\mathrm{m}} \cdot F^{14} \mathrm{C}_{(\mathrm{m})} & =M_{\mathrm{st}} \cdot F^{14} \mathrm{C}_{(\mathrm{st})}+M_{\mathrm{mc}} \cdot F^{14} \mathrm{C}_{(\mathrm{mc})} \\
& +M_{\mathrm{fc}} \cdot F^{14} \mathrm{C}_{(\mathrm{fc})},
\end{aligned}
$$

where $M_{\mathrm{m}}$ is the experimentally determined carbon mass, $F^{14} \mathrm{C}_{(\mathrm{m})}$ the experimentally determined fraction modern, and $F^{14} \mathrm{C}_{(\text {st })}$ the nominal fraction modern of the standard material.

Substituting $F^{14} \mathrm{C}_{(\mathrm{st})}=0$ for the anthracite standard and considering that $F^{14} \mathrm{C}_{(\mathrm{fc})}=0$ and $F^{14} \mathrm{C}_{(\mathrm{mc})}=1$, this equation allows to estimate the mass of modern contamination $M_{\mathrm{mc}}=F^{14} \mathrm{C}_{(\mathrm{m})} \cdot M_{\mathrm{m}}$. Once the modern contamination is known, $M_{\mathrm{fc}}$ can be derived from measurements of the HOxII standard by substituting $F^{14} \mathrm{C}_{(\mathrm{st})}=1.3406, F^{14} \mathrm{C}_{(\mathrm{fc})}=0$ in Eq. (3) and combining with Eq. (2):

$$
\begin{aligned}
M_{\mathrm{fc}} & =\left(\left(1.3406-F^{14} \mathrm{C}_{(\mathrm{m})}\right) \cdot M_{\mathrm{m}}\right. \\
& \left.-(1.3406-1) \cdot M_{\mathrm{mc}}\right) / 1.3406 .
\end{aligned}
$$

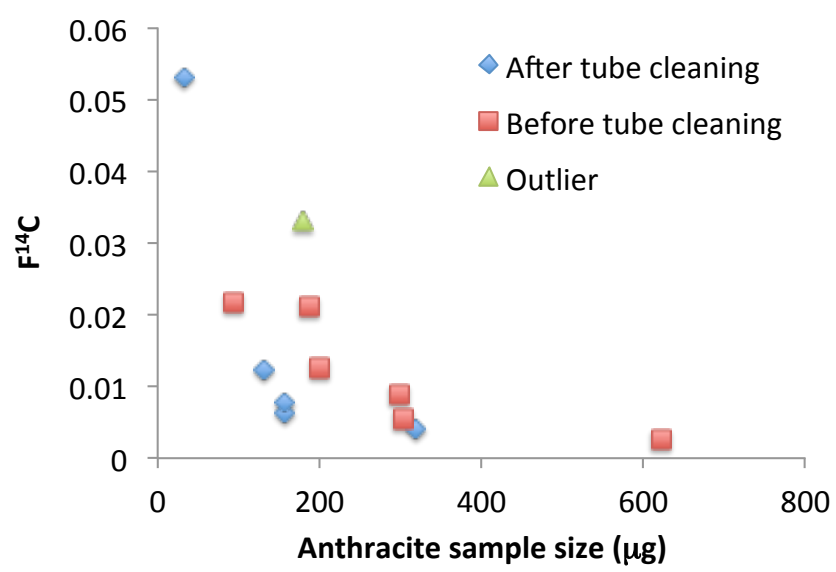

Figure 2. The experimentally determined $F^{14} \mathrm{C}$ of the anthracite standard (nominal $F^{14} \mathrm{C}=0$ ) as a function of sample size. The blue diamonds correspond to samples measured after a new protocol for cleaning the reaction tube was introduced, the red squares before the new protocol. An outlier is shown in green.

\subsubsection{Results}

The direct determination of the contamination from blank filter analysis yields usually around 1-2 $\mu \mathrm{g}$ of carbon/sample for organic carbon (OC) and extracted refractory carbon $\left(\mathrm{EC}_{\mathrm{r}}\right)$, which includes all the contamination introduced by filter cutting and handling. This contamination is not increased by subjecting a clean filter to the water extraction procedure, described in Sect. 2.2. Field blank filters yield on average the same amount of OC and a slightly higher amount of $\mathrm{EC}_{\mathrm{r}}$ of $2 \mu \mathrm{g} \mathrm{C} / \mathrm{sample}$. The latter does not depend strongly on the filter area used. For a typical filter piece of $3 \mathrm{~cm}$ in diameter this amounts to approximately $(0.35 \pm 0.15) \mu \mathrm{g} \mathrm{C} \mathrm{cm}^{-2}$ for OC. For $\mathrm{EC}_{\mathrm{r}}$ extraction, twothree filter pieces are usually analyzed to collect enough material for ${ }^{14} \mathrm{C}$ analysis and therefore the contamination of $\mathrm{EC}_{\mathrm{r}}$ is approximately 0.1 and $0.2 \mu \mathrm{g} \mathrm{C} \mathrm{cm}^{-2}$ for three and two filter pieces, respectively.

The organic fraction of one field blank filter was analyzed for ${ }^{14} \mathrm{C}$ by pooling several extracts of the same filter. This fraction had $F^{14} \mathrm{C}_{(\text {OC, blank })}=(0.797 \pm 0.015)$, which is close to typical ambient $F^{14} \mathrm{C}_{(\mathrm{OC})}$ values. The ${ }^{14} \mathrm{C}$ content of $\mathrm{EC}_{\mathrm{r}}$ was analyzed by pooling $\mathrm{CO}_{2}$ extracted from 5 different blanks that for test purposes were kept in the filter stacks of the sampler not for one minute but for varying amounts of time up to several days without being exposed to the air stream. The time in the sampler had no effect on $\mathrm{EC}_{\mathrm{r}}$ concentrations, which indicates that $\mathrm{EC}_{\mathrm{r}}$ on the blank filter is only introduced by filter handling and thermal extraction. The $F^{14} \mathrm{C}_{(\mathrm{EC} \text {, blank) }}$ for these 5 samples is $(0.543 \pm 0.014)$, which is significantly higher than typical values of $F^{14} \mathrm{C}_{\left(\mathrm{EC}_{\mathrm{r}}, \text { blank }\right)}$ from ambient aerosol samples (e.g., Szidat et al., 2006). The blank correction will therefore shift $F^{14} \mathrm{C}_{\left(\mathrm{EC}_{\mathrm{r}}\right)}$ to lower values. 
Twelve independent measurements of the anthracite standard throughout the time period 2010-2013 yielded a modern contamination $M_{\mathrm{mc}}$ with an average and standard deviation of (1.92 \pm 0.83$) \mu \mathrm{g} C$ per extraction, excluding one outlier of $6 \mu \mathrm{g}$. However, an improved cleaning method for the reaction tube used from 2011 onwards resulted in a lower $M_{\mathrm{mc}}$ to $(1.36 \pm 0.20) \mu \mathrm{g} C$ per extraction for the 5 standards measured in this time period from 2011-2013. The fossil contamination is on average $(1.37 \pm 0.93) \mu \mathrm{g} \mathrm{C}$ per extraction for 12 samples between 2011-2013 and is not influenced by the change in cleaning procedure of the reaction tube. The propagated measurement uncertainties (arising from the uncertainties in ${ }^{14} \mathrm{C}$ measurements and carbon amount) for the average $M_{\mathrm{mc}}$ are smaller than $5 \%$. For the average $M_{\mathrm{fc}}$ the propagated measurement uncertainties are around $30 \%$.

Figure 3 shows the handling blank in $\mu \mathrm{g} \mathrm{C} \mathrm{cm}{ }^{-2}$ for TC, $\mathrm{OC}$ and EC as white bars. For EC the two white bars represent the lower limit of $\sim 0.1 \mu \mathrm{g} \mathrm{cm}^{-2}$, if 3 filter pieces are used for EC extraction and $\sim 0.3 \mu \mathrm{g} \mathrm{cm}^{-2}$, if one filter piece is used. This is compared to the concentration of carbon on a typical small sample, which is shown in black bars. Using materials with known ${ }^{14} \mathrm{C}$ content, the contamination of TC could be assessed by an alternative method and divided into modern contamination $\left(M_{\mathrm{mc}}\right)$ and fossil contamination $\left(M_{\mathrm{fc}}\right)$ as detailed in Eqs. (2)-(4). These are shown as additional grey bars for TC only. The sum of $M_{\mathrm{fc}}$ and $M_{\mathrm{mc}}$ is slightly lower than the total carbon handling blank. The blanks are also compared to a filter sample with a carbon mass concentration in the lower range of typical filter samples used for radiocarbon analysis in our group. For samples with a total carbon concentration $\sim>20 \mu \mathrm{g} \mathrm{cm}^{-2}$, the amount of carbon on a blank filter is less than $5 \%$ of the carbon amount on a typical ambient filter. Therefore, the blank correction does not introduce large uncertainties to the data.

\subsubsection{Discussion}

The contamination introduced by the filter handling and analysis is reasonable compared to expected sample size. The contamination is on the order of $1 \mu \mathrm{g} /$ extraction for OC and EC and probably difficult to reduce even further without special clean room facilities. The sum of $M_{\mathrm{fc}}$ and $M_{\mathrm{mc}}$, which is more indicative of the contamination introduced by the thermal extraction system, is lower than the total carbon handling blank. Figure 2 indicates that contamination from filter handling contributes roughly $1 / 3$ to the total blank.

\subsection{Loss of elemental carbon at $\mathrm{OC}$ combustion temperatures}

\subsubsection{Test procedure}

Several studies show that when heating different kinds of soot in $\mathrm{He}-\mathrm{O}_{2}$ mixtures or air, a small mass loss can start already at fairly low temperatures of around $300^{\circ} \mathrm{C}$ (e.g.,

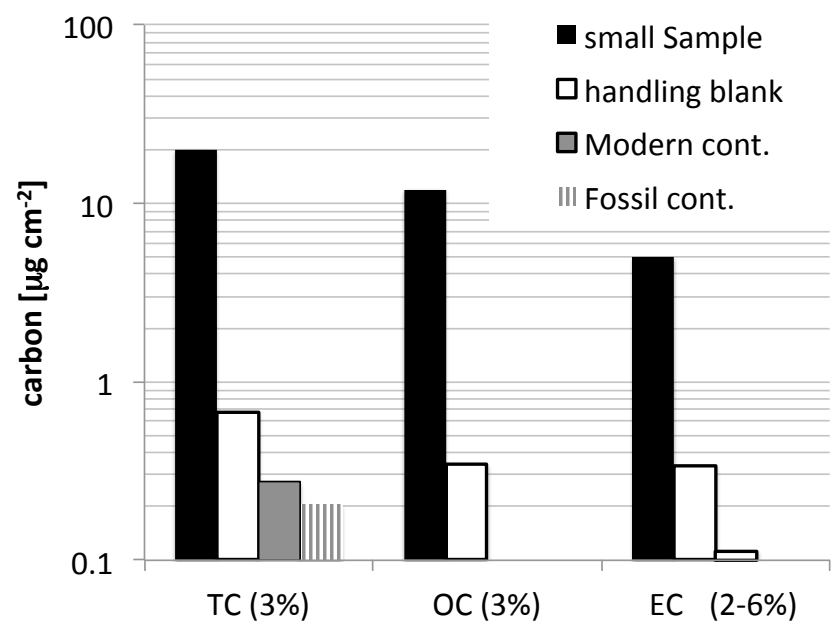

Figure 3. The carbon concentration found on a typical lightly loaded filter sample compared with the directly measured handling blank (white bars), and the average modern and fossil contamination derived from analysis of anthracite and HOxII standards. The modern and fossil contamination could only be determined for total carbon. The two white bars for EC give an upper and lower limit of the handling blank, depending on the number of filter pieces used in the extraction.

Sharma et al., 2012; Su et al., 2004). To test for loss of EC at temperatures that are typically used to combust $\mathrm{OC}$ we used commercial carbon black samples (Elftex), which is often regarded as an appropriate surrogate for diesel soot (e.g., Yezerets, 2005, and references therein). The carbon black was applied to quartz fiber filters as described in Sect. 2.3. Before analysis, the filters were heated at $100^{\circ} \mathrm{C}$ in oxygen to remove any ethanol that might have adsorbed on the filter during the application of the carbon black suspension. The filters were then exposed to $340^{\circ} \mathrm{C}$ in pure $\mathrm{O}_{2}$ for up to two hours and the amount of $\mathrm{CO}_{2}$ evolved during this time was determined manometrically. Blank filters spiked with only deionized water and ethanol were analyzed in the same way and the carbon amount found on the blank filter (around $1 \mu \mathrm{g} \mathrm{cm}^{-2}$ ) was subtracted from all analyzed filters.

\subsubsection{Results}

Figure 4 shows the loss of carbon black material at $340{ }^{\circ} \mathrm{C}$ in $\mathrm{O}_{2}$ as a function of oxidation time for two types of quartz fiber filters, namely circular Whatman QMA 1851-150 (Filter 2) as used for the ambient samples in this study, compared with a square Whatman QMA No: 1851-865 (Filter 1), which was already several years old. The loss of carbon black increases linearly with oxidation time and the rate is roughly half for filter 2. Impurities in the filter material can catalyze the loss of soot and this example shows that the quartz fiber filter material itself can make a difference in the rate of oxidation of soot. On filter type 1, which was used in all subsequent studies with this system, approximately $1.5 \mathrm{~h}$ are 
necessary to oxidize $10 \%$ of the carbon black at $340{ }^{\circ} \mathrm{C}$. Considering that the filter is only heated for $15 \mathrm{~min}$ for OC determination, the loss of carbon black in this time period is less than $3 \%$. In ambient aerosol the concentration of EC is usually significantly smaller than the concentration of OC. Assuming that typically $20-30 \%$ of total carbon consists of EC the contribution of prematurely evolved EC to the extracted OC should be below $1 \%$, if carbon black is a suitable model for atmospheric EC.

\subsubsection{Discussion}

Several studies (e.g., Sharma et al., 2012; Han et al., 2007) show that most carbon black samples are somewhat more thermally refractory than diesel soot, which in turn seems to be more refractory than soot from wood burning, at least with respect to the thermal-chemical oxidation method (Song et al., 2012). Therefore, the carbon black experiments can give a reasonable estimate for the loss of more refractory types of soot, but it must be kept in mind that some types of soot or char can be less refractory than carbon black. However, it is reasonable to assume that even for less refractory types of soot the contribution of prematurely evolved EC to the OC sample will not exceed a few percent.

This is supported by indirect evidence gained by combustion of an ambient filter sample at increasing temperatures of $300,320,340,360$, and $380^{\circ} \mathrm{C}$ (not shown). If prematurely oxidized EC significantly contributed to the $\mathrm{OC}$ that is combusted at these temperatures, this contribution should increase at higher temperatures. This would cause a decrease of $F^{14} \mathrm{C}_{(\mathrm{OC})}$ with oven temperature, since the $F^{14} \mathrm{C}_{(\mathrm{EC})}$ is usually considerably smaller than $F^{14} \mathrm{C}_{(\mathrm{OC})}$. Even though the amount of extracted $\mathrm{OC}$ increased with oven temperature and was $30 \%$ higher at $380^{\circ} \mathrm{C}$ than at $300^{\circ} \mathrm{C}, F^{14} \mathrm{C}_{(\mathrm{OC})}$ remained at $0.809 \pm 0.013 \%$, independent of the oven temperature. A similar result was found by Szidat et al. (2004), who also concluded that the influence of prematurely evolved $\mathrm{EC}$ on $F^{14} \mathrm{C}_{(\mathrm{OC})}$ is negligible.

\subsection{Charring of organic test compounds}

\subsubsection{Test procedure}

Charring of organic compounds during thermal desorption is often monitored by optical methods, such as a laser beam, to detect an increase in the light absorption through a filter. This is especially useful when the heating of a filter occurs in an inert gas, where charring is substantial and loss of EC is negligible. When combusting a filter in pure $\mathrm{O}_{2}$, charring is significantly reduced, especially after water extraction. A small loss of EC could partially offset the small increase in light absorption caused by charring. It can therefore be difficult to conclusively quantify charring by optical methods, especially on highly loaded filters such as often used for ${ }^{14} \mathrm{C}$ analysis.

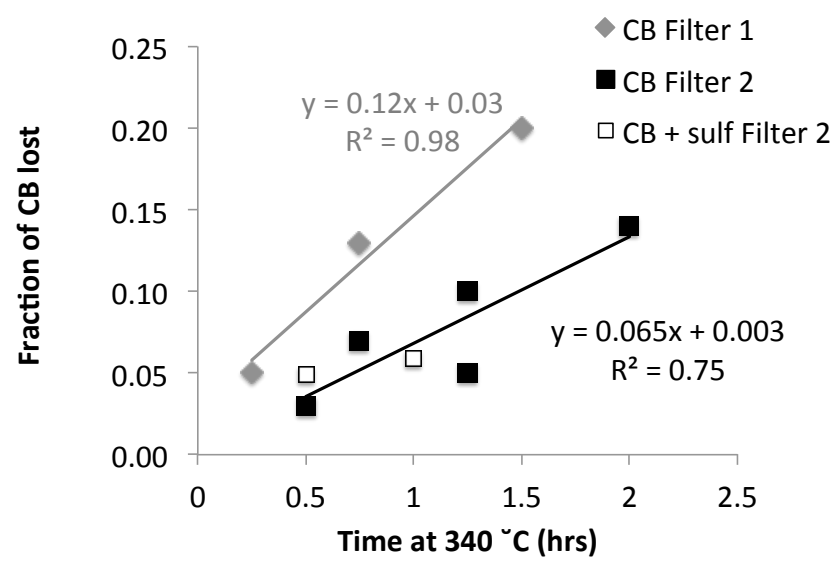

Figure 4. Fraction of carbon black (CB) that was lost at $340{ }^{\circ} \mathrm{C}$ in pure oxygen as a function of oxidation time for two different filter types from the same manufacturer (Filter 1: Whatman QMA 1851865 and Filter 2: Whatman QMA 1851-150). The open squares correspond to carbon black coated with ammonium sulfate

We therefore used representative organic test materials described in Sect. 2.3 to investigate their charring characteristics directly. The test compounds were applied to pre-cleaned quartz fiber filters. The filters were introduced into oven 1 at $340^{\circ} \mathrm{C}$ for $15 \mathrm{~min}$ and the amount of evolved $\mathrm{CO}_{2}$ was determined manometrically. The combustion step at $340^{\circ} \mathrm{C}$ was repeated a second time to verify that all $\mathrm{OC}$ was oxidized during the first combustion step. Then the filter was introduced into oven 2 at $650{ }^{\circ} \mathrm{C}$ and the evolved $\mathrm{CO}_{2}$ was measured. Since only organic and no refractory carbon was present on the filter originally, the $\mathrm{CO}_{2}$ measured at $650^{\circ} \mathrm{C}$ originates from the char that was formed during the combustion of the organic test material.

\subsubsection{Results}

Figure 5 shows that charring is small for all investigated compounds during flash heating in $\mathrm{O}_{2}$. Less than $2 \%$ of glucose, of humic acid, of the hydrocarbon standard mix, and of the fatty acid methyl ester (FAME) mix is found as refractory carbon after the first OC combustion step. Charring is slightly higher for organic acids, of which $3.5 \%$ are found as refractory carbon. However, these are normally only a small fraction of the total organic carbon in ambient aerosols. Moreover, they are largely removed by water extraction of the filter prior to EC analysis. In general, our results imply that 1-2\% of the water insoluble $\mathrm{OC}$ is found as $\mathrm{EC}_{\mathrm{r}}$. Even this small amount can have a measurable effect on $F^{14} \mathrm{C}_{\left(\mathrm{EC}_{\mathrm{r}}\right)}$, because $\mathrm{EC}_{\mathrm{r}}$ constitutes usually a small fraction of TC. Assuming that elemental carbon is around $20 \%$ of total carbon, then around $5 \%$ of the analyzed $\mathrm{EC}_{\mathrm{r}}$ can be charred organic carbon. In the extreme case of completely fossil $\mathrm{EC}\left(F^{14} \mathrm{C}_{(\mathrm{EC})}=0\right)$ and biogenic OC $\left(F^{14} \mathrm{C}_{(\mathrm{OC})} \sim 1\right)$, this would increase $F^{14} \mathrm{C}_{(\mathrm{EC})}$ by 0.05 (absolute). If $F^{14} \mathrm{C}_{(\mathrm{OC})}$ is lower and $F^{14} \mathrm{C}_{(\mathrm{EC})}$ is 


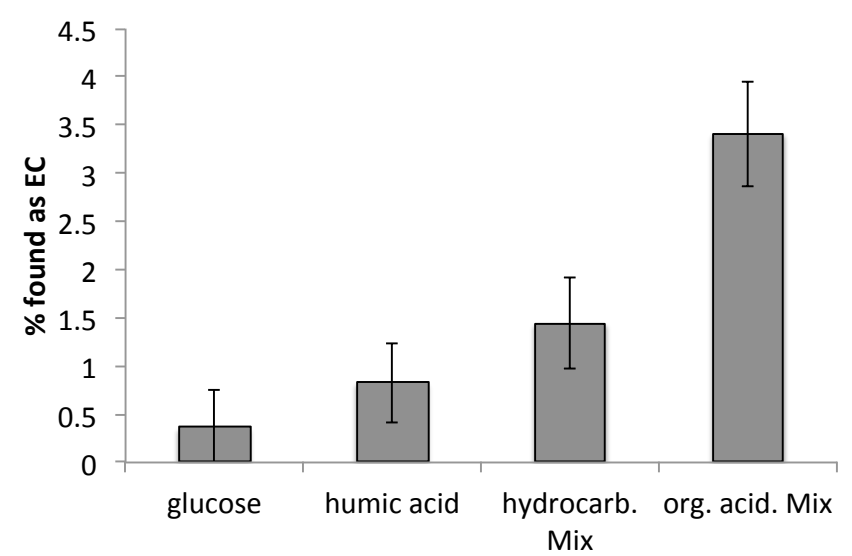

Figure 5. Charring of several test compounds given as $\%$ of the substance found as EC after heating at $340^{\circ} \mathrm{C}$ for $15 \mathrm{~min}$ in pure oxygen.

higher than in this extreme case, the overestimate is smaller (e.g., 0.03 for $F^{14} \mathrm{C}_{(\mathrm{OC})} \sim 0.8$ and $F^{14} \mathrm{C}_{(\mathrm{EC})} \sim 0.2$ ).

\subsubsection{Discussion}

Removal of organic carbon by flash heating in $\mathrm{O}_{2}$ was originally developed to minimize the charring artifact (Cachier et al., 1989) and from our tests it is clear that this approach is very successful for water insoluble compounds, but less successful for water soluble carbon. WSOC usually also accounts for the majority of charring during heating under inert atmospheres (e.g., Yu et al., 2002). Zhang et al. (2012) used laser transmission measurements to monitor charring during the OC combustion steps. They combusted the water extract of an ambient aerosol sample, which showed even higher charring than the organic acids investigated in this work. However, for water extracted ambient samples they also concluded that the contribution from charred OC to the extracted EC can be reduced to below $5 \%$ for ambient samples. This indicates that the water insoluble test compounds chosen for our charring test are representative of the ambient water insoluble aerosol. This makes them a useful substitute for evaluating charring in OC-EC separation systems that lack optical monitoring. Cachier et al. (1989) found a higher percentage of charred humic acids remaining on the filter $(\sim 30 \%)$ and somewhat higher amounts of charred glucose ( $\sim 10 \%$ for filter loadings comparable to our work). The reason for this difference is not clear.

\subsection{Tests with ambient filters}

\subsubsection{Test procedure}

During the charring tests we found that, except for a small charred fraction, all organic test compounds used in this study were removed after combustion at $340^{\circ} \mathrm{C}$ for $15 \mathrm{~min}$ in pure $\mathrm{O}_{2}$, even high molecular weight humic acid. However, the continuous transition from $\mathrm{OC}$ to the most refractory carbon in form of elemental carbon nanospheres in ambient aerosols is difficult to capture using simple test compounds. Therefore ambient samples are also used to test the efficiency of separating OC and EC in ambient aerosols.

The extraction methods usually utilize a practical compromise by excluding compounds with intermediate refractivity from the analysis. A short intermediate step $\mathrm{S} 2$ in $\mathrm{O}_{2}$ at higher temperature should remove a mixture of the most refractory organic material and less refractory elemental carbon from the filter (e.g., Szidat et al., 2006; Zhang et al., 2012). However, the use of too harsh oxidation methods that allow only the most refractory part of EC to be recovered have the disadvantage that biomass burning $\mathrm{EC}$ is removed to a somewhat larger extent than fossil EC. Biomass burning soot is less refractory than soot from liquid fuels (e.g., Song et al., 2012; Zhang et al., 2012) and has been found to evolve together with chars during thermal treatments rather than with diesel soot. Preferential removal of biomass burning soot thus artificially decreases $F^{14} \mathrm{C}_{\left(\mathrm{EC}_{\mathrm{r}}\right)}$ which leads to an underestimate of the fraction modern of EC.

We therefore investigate how different choices of parameters for extraction step S2 (with temperature for S1 remaining constant at $340{ }^{\circ} \mathrm{C}$ ) affect (1) the recovery of EC and (2) the efficiency of $\mathrm{OC}$ removal. A water-extracted filter was kept in the first oven for $15 \mathrm{~min}$ for OC combustion (S1). Then it was introduced into the second oven at a higher temperature $T_{2}$ for 1-3 min and the $\mathrm{CO}_{2}$ that evolved during this extraction step was pumped away. Then the filter was taken out of the oven system, while the $\mathrm{CO}_{2}$ resulting from the combustion step S1 was purified and processed. For the last step, the filter was introduced into oven 2 at $650^{\circ} \mathrm{C}$ and $\mathrm{EC}_{\mathrm{r}}$ was measured.

The complete removal of $\mathrm{OC}$ is difficult to assess directly. However, two indirect estimates are used that can indicate the extent of OC removal. First, refractory OC is often associated with highly polymeric, char- or tar-like substances. These substances are often subsumed under the name "brown carbon" $(\mathrm{BrC})$, which is characterized by its light absorption properties (e.g., Andreae and Gelencsér, 2006; Pöschl, 2005). The recovery of EC was estimated by comparing the light absorption of a water extracted filter piece to the absorption of a filter piece after organic carbon was removed during S1 and S2. Absorption was measured using an integrating sphere photometer (Hitzenberger et al., 1996; Wonaschütz et al., 2009). BC and $\mathrm{BrC}$ concentrations were determined by measuring the light absorption of the filter pieces at 3 different wavelengths. $\mathrm{BrC}$ is distinguished from $\mathrm{BC}$ by exploiting the different wavelength dependence of light absorption following Wonaschütz et al. (2009). If brown carbon is removed after S1 and S2, this gives a good indication that the extraction protocol was effective in removing most refractory OC.

A second method is to measure the mass and $F^{14} \mathrm{C}$ of the refractory carbon $\mathrm{EC}_{\mathrm{r}}$ as a function of increasing temperature and/or duration of step S2. If a decrease in recovered mass is 


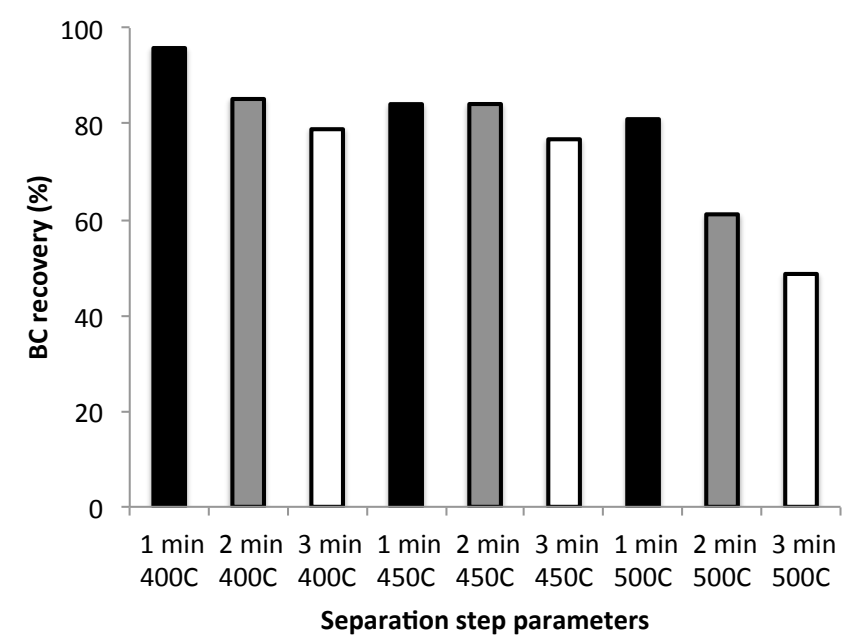

Figure 6. Black carbon recovery as a function of duration and temperature of separation step S2.

associated with a strong decrease in $F^{14} \mathrm{C}_{\left(\mathrm{EC}_{\mathrm{r}}\right)}$, this can be an indication that fairly "modern" organic material is still being removed when the temperature of step S2 is increased. Preferential removal of biomass burning $\mathrm{EC}$ is usually associated with a much more gradual decrease in $F^{14} \mathrm{C}_{\left(\mathrm{EC}_{\mathrm{r}}\right)}$.

\subsubsection{Results}

The effect of the duration and temperature of $\mathrm{S} 2$ on the recovery of black carbon are shown in Fig. 6 for filter CA18. A duration of $\mathrm{S} 2$ of 1 min causes loss of black carbon that does not exceed $20 \%$. There is little change in black carbon content between a filter that has been exposed to 450 and $500^{\circ} \mathrm{C}$ for $1 \mathrm{~min}$, which suggests that $1 \mathrm{~min}$ of heating might not be enough for the filter temperature to fully reach $500^{\circ} \mathrm{C}$. When the duration of S2 is increased to two minutes an increase in temperature from 400 to $450^{\circ} \mathrm{C}$ causes little extra loss of BC. The amount of BC remaining after $\mathrm{S} 2$ of $450{ }^{\circ} \mathrm{C}$ is very similar for exposure times of 1 and $2 \mathrm{~min}$, suggesting that little additional $\mathrm{BC}$ is removed by increasing the oxidation time. However, raising the temperature further to $500^{\circ} \mathrm{C}$ strongly decreases the recovered $\mathrm{BC}$ to around $60 \%$. If the duration of S2 is increased to $3 \mathrm{~min}$, then the recovery at 400 and $450{ }^{\circ} \mathrm{C}$ decreases by only $8 \%$ and remains comparable, whereas the recovery at $500{ }^{\circ} \mathrm{C}$ decreases sharply to $50 \%$. This indicates that a temperature $500^{\circ} \mathrm{C}$ is too high, since substantial amounts of $\mathrm{BC}$ are removed. A time step of $1 \mathrm{~min}$ is likely too short for the filter to reach the desired temperature, therefore a step of $2 \mathrm{~min}$ was tried for further experiments.

$F^{14} \mathrm{C}_{(\mathrm{EC})}$ of filter CA12 was measured as function of $\mathrm{S} 2$ temperature with S2 duration of 2 min. Figure 7a shows that the amount of remaining $\mathrm{EC}_{\mathrm{r}}$ (black bars) decreases only slightly if the $\mathrm{S} 2$ temperature is raised from 400 to $450{ }^{\circ} \mathrm{C}$, but only $50 \%$ of the original EC remains after 2 min at
$500{ }^{\circ} \mathrm{C} . F^{14} \mathrm{C}_{\left(\mathrm{EC}_{\mathrm{r}}\right)}$ (grey bars) remains virtually unchanged for $\mathrm{S} 2$ temperatures of 400 and $450^{\circ} \mathrm{C}$ and then decreases from 0.36 to 0.31 once the $\mathrm{S} 2$ temperature is raised to $500^{\circ} \mathrm{C}$. $F^{14} \mathrm{C}$ of the material removed by each successive temperature increase can be calculated according to the mass balance:

$$
\begin{aligned}
F^{14} \mathrm{C}_{(2-1)} & =\left(F^{14} \mathrm{C}_{(\mathrm{EC} 1)} \cdot M_{\mathrm{EC}}\left(T_{1}\right)\right. \\
& \left.-F^{14} \mathrm{C}_{(\mathrm{EC} 2)} \cdot M_{\mathrm{EC}}\left(T_{2}\right)\right) /\left(M_{\mathrm{EC}}\left(T_{1}\right)-M_{\mathrm{EC}}\left(T_{2}\right)\right),
\end{aligned}
$$

where $F^{14} \mathrm{C}_{(2-1)}$ is the fraction modern of the material that was removed by raising $\mathrm{S} 2$ temperature from $T_{1}$ to $T_{2}$; $F^{14} \mathrm{C}_{(\mathrm{EC} 1)}, F^{14} \mathrm{C}_{(\mathrm{EC} 2)}$ are the fraction modern of the refractory carbon recovered after $T_{1}$ and $T_{2} ; M_{\mathrm{EC}}\left(T_{1}\right)$ and $M_{\mathrm{EC}}\left(T_{2}\right)$ are the mass of the refractory carbon recovered after $T_{1}$ and $T_{2}$. These are shown in Fig. 7a as patterned bars. It is obvious that the removed carbon has a similar fraction modern as the $\mathrm{EC}_{\mathrm{r}}$ itself, which suggests that the largest amount of organic carbon was removed already at $\mathrm{S} 2$ of $400^{\circ} \mathrm{C}$ and the higher temperature steps remove mainly EC. The slight decrease in $F^{14} \mathrm{C}$ with increasing $\mathrm{S} 2$ temperature results more likely from differential oxidation of biomass burning $\mathrm{EC}$ and fossil fuel EC, than from remaining organic carbon. If organic carbon was left in the sample a larger decrease in $F^{14} \mathrm{C}_{(\mathrm{EC})}$ between 400 and $450{ }^{\circ} \mathrm{C}$ would be expected than at a temperature that is high enough to burn significant amounts of black carbon.

Figure $7 \mathrm{~b}$ shows similar results for a $1 \mathrm{~min}$ S2 time step. Filter CA2 was used for these experiments, since not enough material was left of filter CA12 for further tests. An increase in temperature of $\mathrm{S} 2$ from 400 to $500^{\circ} \mathrm{C}$ does not cause a strong decrease in the recovered EC. A similar trend was observed for the black carbon concentrations shown in Fig. 6. This supports our conclusion that the filter itself probably does not reach $500^{\circ} \mathrm{C}$ within $1 \mathrm{~min}$. However, even though not much extra material is removed during $1 \mathrm{~min}$ at $500^{\circ} \mathrm{C}$, the fraction modern of the recovered EC decreases significantly. Following mass balance Eq. (6), $F{ }^{14} \mathrm{C}$ of the carbon removed by raising $T$ to $500^{\circ} \mathrm{C}$ is 0.67 , very close to the $F^{14} \mathrm{C}$ of water insoluble organic carbon of filter CA2 (0.62). This shows that a time period of $1 \mathrm{~min}$ for the intermediate step S2 is probably not sufficient to remove all organic carbon from the filter.

The final decision was to use a $\mathrm{S} 2$ temperature step of $2 \mathrm{~min}$ at $450^{\circ} \mathrm{C}$, because this combines reasonable $\mathrm{BC}$ recovery rates with removal of most refractory OC. For $T_{1}$ we decided to use a temperature of $360^{\circ} \mathrm{C}$, since this gives a higher recovery rate of $\mathrm{OC}$ on some highly loaded samples. Varying the temperature of step 1 did not change $F^{14} \mathrm{C}_{(\mathrm{OC})}$ and showed only minimal loss of carbon black material, which both indicates that this slightly higher temperature should not strongly affect $\mathrm{EC}$ recovery and consequently $F^{14} \mathrm{C}_{\left(\mathrm{EC}_{\mathrm{r}}\right)}$.

This temperature protocol was tested on 4 ambient filter samples with respect to removal of brown carbon and EC 
Table 1. Brown carbon $(\mathrm{BrC})$ and black carbon $(\mathrm{BC})$ detected in 4 ambient filter samples before OC removal and after OC removal (OC rem.) using $\mathrm{S} 1$ at $360^{\circ} \mathrm{C}$ for $15 \mathrm{~min}$ and $\mathrm{S} 2$ at $450^{\circ} \mathrm{C}$ for $2 \mathrm{~min}$ in pure oxygen. mar - Filter with back trajectories starting over the ocean, cont - Filter with back trajectories starting over the land. Also shown is the $\mathrm{BC}$ recovery, $F^{14} \mathrm{C}$ of the recovered $\mathrm{EC}\left(\mathrm{EC}_{\mathrm{r}}\right)$ and the extrapolated $F^{14} \mathrm{C}$ for $100 \%$ recovery $\left(\mathrm{EC}_{\mathrm{t}}\right)$. For the extrapolation we take the average slope of $F^{14} \mathrm{C}$ with optical recovery $(0.31)$ from the supporting material in Zhang et al. (2012).

\begin{tabular}{lllrrrrr}
\hline & $\begin{array}{l}\text { BrC } \\
\text { sample }\end{array}$ & $\begin{array}{l}\mathrm{g} \mathrm{cm}^{-1} \\
\mu \mathrm{g} \mathrm{cm}^{-1}\end{array}$ & $\begin{array}{r}\mathrm{BC} \\
\mu \mathrm{g} \mathrm{cm}^{-1}\end{array}$ & $\begin{array}{r}\mathrm{BC} \\
(\mathrm{OC} \text { rem. }) \\
\mu \mathrm{g} \mathrm{cm}^{-1}\end{array}$ & $\begin{array}{r}\mathrm{BC} \\
\text { recovery } \\
\%\end{array}$ & $F^{14} \mathrm{C}_{\left(\mathrm{EC}_{\mathrm{r}}\right)}$ & $F^{14} \mathrm{C}_{\left(\mathrm{EC}_{\mathrm{t}}\right)}$ \\
\hline CA30 - mar & 3.81 & $\mathrm{bdl}^{*}$ & 13.21 & 11.08 & 84 & 0.14 & 0.19 \\
CA59 - mar & $\mathrm{bdl}^{*}$ & $\mathrm{bdl}^{*}$ & 2.80 & 2.21 & 79 & 0.10 & 0.17 \\
CA85 - cont & 21.54 & $\mathrm{bdl}^{*}$ & 15.04 & 11.86 & 79 & 0.30 & 0.36 \\
CA21 - cont & 15.62 & $\mathrm{bdl}^{*}$ & 11.71 & 12.63 & 108 & 0.39 & n.a. \\
\hline
\end{tabular}

* bld: below detection limit $<2 \mu \mathrm{g} \mathrm{cm}{ }^{-2}$.
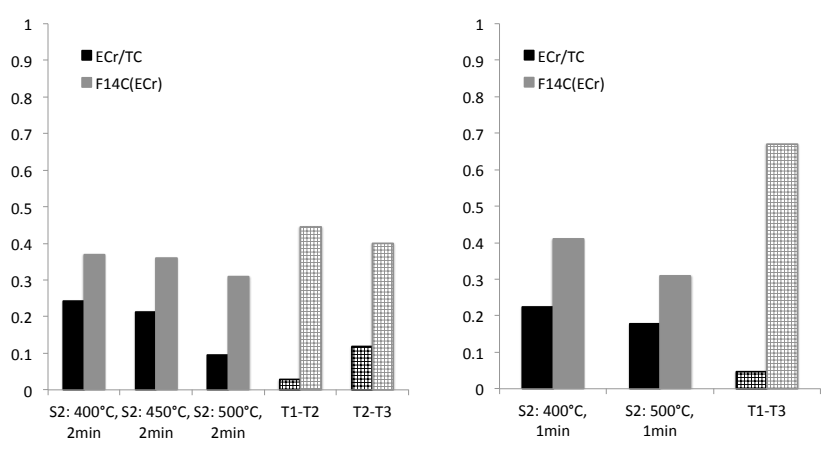

Figure 7. Fraction modern and mass fraction $\left(\mathrm{EC}_{\mathrm{r}} / \mathrm{TC}\right)$ of the extracted refractory carbon $\left(\mathrm{EC}_{\mathrm{r}}\right)$ remaining after a separation step $\mathrm{S} 1$ $\left(15 \mathrm{~min}\right.$ at $\left.360^{\circ} \mathrm{C}\right)$ and $\mathrm{S} 2$. The duration and temperature of separation $\mathrm{S} 2$ are given on the $x$ axis. The difference in $\mathrm{EC}_{\mathrm{r}} / \mathrm{TC}$ and $F^{14} \mathrm{C}$ $\left(\mathrm{EC}_{\mathrm{r}}\right)$ found after extraction step S2 at lower and higher temperature are given as shaded bars.

recovery. Two of the samples had marine air mass origin, whereas the other two had continental air mass origin. The two samples with marine air mass origin contain little water insoluble brown carbon (Table 1), whereas the continental samples contain significant amounts. After OC removal the brown carbon is below detection level for all test filters, which is further indication for satisfactory removal of the organic fraction. The recovery of BC is approximately $80 \%$ for three of the filters, which is close to the target value for which the S2 step was chosen. However, for filter CA21 the recovery is slightly above $100 \%$. Filter CA21 was sampled for a week during fairly high aerosol concentrations and has therefore a very high aerosol loading $\left(\mathrm{TC}=219 \mu \mathrm{g} \mathrm{cm}^{-2}\right.$ ). It is possible that the saturation of the integrating sphere method is reached and a small loss of $\mathrm{BC}$ cannot be detected. However, is also possible that $2 \mathrm{~min}$ at $450{ }^{\circ} \mathrm{C}$ are not enough to remove such large amounts of $\mathrm{OC}$ that is coating the BC. However, since all the brown carbon is nevertheless removed, this does not seem very likely. Alternatively, a fairly high amount of brown carbon that is relatively susceptible to charring could produce measurable amounts of black carbon during $\mathrm{S} 1$ and $\mathrm{S} 2$. The $F^{14} \mathrm{C}_{\left(\mathrm{EC}_{\mathrm{r}}\right)}$ values of filter samples with a $\mathrm{BC}$ recovery of $\sim 1$ should be treated with caution, and possibly the extraction procedure should be repeated either with higher temperature or longer duration of $\mathrm{S} 2$.

In the last column of Table 1 we show $F^{14} \mathrm{C}_{\left(\mathrm{EC}_{\mathrm{t}}\right)}$, the fraction modern estimated for the total elemental carbon at $100 \%$ recovery, assuming that biomass burning EC is lost to a greater degree than fossil EC during S2. The relationship between $F^{14} \mathrm{C}_{(\mathrm{EC})}$ and optical recovery is taken from the supplementary material in Zhang et al. (2012).

\subsubsection{Discussion}

The amount and $F^{14} \mathrm{C}$ as well as optical properties of $\mathrm{EC}_{\mathrm{r}}$ suggest that an $\mathrm{S} 2$ time removal step of $2 \mathrm{~min}$ around $450^{\circ} \mathrm{C}$ is a good choice for separating organic and refractory carbon. Two other methods published in the literature (Zhang et al., 2012; Bernardoni et al., 2013) use a similar approach but different combustion temperatures and atmospheres. Each is evaluated with different methods, but some main conclusions are similar. The black carbon recovery by the presented method $(\sim 80 \%)$ is similar to the one reported for the Swiss S4 protocol (Zhang et al., 2012) and slightly higher than in the method proposed by Bernardoni et al. (2013). The contamination of $\mathrm{EC}_{\mathrm{r}}$ with charged $\mathrm{OC}$ is estimated to be $<5 \%$ in this work and Zhang et al. (2012). This similar performance in different test procedures gives additional confidence in these methods.

The method presented in this work does not use a He step, which the other methods find necessary to remove a non light absorbing carbon fraction that co-evolves with $\mathrm{BC}$ in $\mathrm{O}_{2}$ up to very high temperatures. At present it is not clear whether this carbon fraction is truly organic, such as pollen or other refractory bio-polymers or whether it might be elemental carbon that is potentially not so strongly light absorbing, such as the more amorphously oriented carbon layers seen by Gustafsson et al. (2001). 
A future inter-comparison of these three and also other methods (e.g., Zencak et al., 2007; Heal et al., 2011) would shed more light on the issue how strongly the differences in the extraction protocols affect $F^{14} \mathrm{C}_{\left(\mathrm{EC}_{\mathrm{r}}\right)}$. Such an intercomparison has been done for organic and total carbon (Szidat et al., 2013), but only very limited data on EC were available at that time.

\section{Conclusions}

We tested a thermal method designed to separate organic and combustion derived refractory carbon for radiocarbon analysis of aerosol samples. For OC extraction the sample is combusted in pure oxygen at $360^{\circ} \mathrm{C}$ for $15 \mathrm{~min}$. For EC extraction a water-extracted filter sample is first subjected to $360^{\circ} \mathrm{C}$ for $15 \mathrm{~min}$, followed by a $2 \mathrm{~min}$ intermediate combustion step at $450{ }^{\circ} \mathrm{C}$ to completely remove OC. After OC removal EC is extracted at $650^{\circ} \mathrm{C}$ for $15 \mathrm{~min}$.

The recovery of EC after the OC removal steps was quantified by measuring the recovery of black carbon (BC) using an optical method. The BC recovery was around $80 \%$, which is comparable to two similar methods (Zhang et al., 2012; Bernardoni et al., 2013). The effectiveness of the OC removal steps are strongly supported by the successful removal of brown carbon in 4 ambient test samples and by the removal of several organic test compounds, including high molecular weight humic acid.

Charring of water insoluble organic test materials was found to be minor. Less than $2 \%$ of the organic test compounds were found as EC after the OC combustion step. From this we estimate that around $5 \%$ of EC could originate from charred OC. This is in close agreement with Zhang et al. (2012), who estimated charring of ambient samples using optical methods.

Acknowledgements. This work was funded by the Dutch science foundation (NWO, grant No. 820.01.001). The development of the $\mathrm{BC}$ analysis technique was funded by the Hochschuljubiläumstiftung der Stadt Wien, grant H-85/92. We would like to thank Dicky van Zonneveld, Henk Been and Anita Aerts-Bijma for their ${ }^{14} \mathrm{C}$ analysis work. We thank Robert Wagner und Elisabeth Traxler for their help with black and brown carbon analysis. We would like to thank Sönke Szidat and one anonymous reviewer for valuable comments on the manuscript.

Edited by: P. Herckes

\section{References}

Andreae, M. O. and Gelencsér, A.: Black carbon or brown carbon? The nature of light-absorbing carbonaceous aerosols, Atmos. Chem. Phys., 6, 3131-3148, doi:10.5194/acp-6-3131-2006, 2006.

Bernardoni, V., Calzolai, G., Chiari, M., Fedi, M., Lucarelli, F., Nava, S., Piazzalunga, A., Riccobono, F., Taccetti, F., Valli, G., and Vecchi, R.: Radiocarbon analysis on organic and elemental carbon in aerosol samples and source apportionment at an urban site in Northern Italy, J. Aerosol Sci., 56, 88-99, doi:10.1016/j.jaerosci.2012.06.001, 2013.

Cachier, H., Bremond, M.-P., and Buat-Menart, P.: Determination of atmospheric soot carbon with a simple thermal method, Tellus B, 41, 379-390, 1989.

Currie, L. A.: Evolution and multidisciplinary frontiers of $\mathrm{C}^{14}$ aerosol science, Radiocarbon, 42, 115-126, 2000.

de Rooij, M., van der Plicht, J., and Meijer, H. A. J.: Porous iron pellets for AMS $\mathrm{C}^{14}$ analysis of small samples down to ultramicroscale size (10-25 $\mu \mathrm{g}$ C), Nucl. Instrum. Meth. B, 268, 947951, doi:10.1016/j.nimb.2009.10.071, 2010.

Dusek, U., ten Brink, H. M., Meijer, H. A. J., Kos, G., Mrozek, D., Rockmann, T., Holzinger, R., and Weijers, E. P.: The contribution of fossil sources to the organic aerosol in the Netherlands, Atmos. Environ., 74, 169-176, doi:10.1016/j.atmosenv.2013.03.015, 2013.

El Haddad, I., Marchand, N., Wortham, H., Piot, C., Besombes, J.L., Cozic, J., Chauvel, C., Armengaud, A., Robin, D., and Jaffrezo, J.-L.: Primary sources of $\mathrm{PM}_{2.5}$ organic aerosol in an industrial Mediterranean city, Marseille, Atmos. Chem. Phys., 11, 2039-2058, doi:10.5194/acp-11-2039-2011, 2011.

Gelencser, A., May, B., Simpson, D., Sanchez-Ochoa, A., Kasper-Giebl, A., Puxbaum, H., Caseiro, A., Pio, C., and Legrand, M.: Source apportionment of PM2.5 organic aerosol over Europe: Primary/secondary, natural/anthropogenic, and fossil/biogenic origin, J. Geophys. Res., 112, D23S04, doi:10.1029/2006JD008094, 2007.

Genberg, J., Hyder, M., Stenström, K., Bergström, R., Simpson, D., Fors, E. O., Jönsson, J. Å., and Swietlicki, E.: Source apportionment of carbonaceous aerosol in southern Sweden, Atmos. Chem. Phys., 11, 11387-11400, doi:10.5194/acp-1111387-2011, 2011.

Gilardoni, S., Vignati, E., Cavalli, F., Putaud, J. P., Larsen, B. R., Karl, M., Stenström, K., Genberg, J., Henne, S., and Dentener, F.: Better constraints on sources of carbonaceous aerosols using a combined ${ }^{14} \mathrm{C}$ - macro tracer analysis in a European rural background site, Atmos. Chem. Phys., 11, 5685-5700, doi:10.5194/acp-11-5685-2011, 2011.

Glasius, M., la Cour, A., and Lohse, C.: Fossil and nonfossil carbon in fine particulate matter: A study of five european cities, J Geophys. Res., 116, D11302, doi:10.1029/2011JD015646, 2011.

Godwin, H.: Half-life of radiocarbon, Nature, 195, 984-986, 1962.

Gustafsson, O., Bucheli, T. D., Kukulska, Z., Andersson, M., Largeau, C., Rouzaud, J. N., Reddy, C. M., and Eglinton, T. I.: Evaluation of a protocol for the quantification of black carbon in sediments, Global Biogeochem. Cy., 15, 881-890, doi:10.1029/2000GB001380, 2001.

Hammes, K., Schmidt, M. W. I., Smernik, R. J., Currie, L. A., Ball, W. P., Nguyen, T. H., Louchouarn, P., Houel, S., Gustafsson, Ö., Elmquist, M., Cornelissen, G., Skjemstad, J. O., Masiello, 
C. A., Song, J., Peng, P., Mitra, S., Dunn, J. C., Hatcher, P. G. Hockaday, W. C., Smith, D. M., Hartkopf-Fröder, C., Böhmer, A., Lüer, B., Huebert, B. J., Amelung, W., Brodowski, S., Huang, L., Zhang, W., Gschwend, P. M., Flores-Cervantes, D. X., Largeau, C., Rouzaud, J.-N., Rumpel, C., Guggenberger, G., Kaiser, K., Rodionov, A., Gonzalez-Vila, F. J., Gonzalez-Perez, J. A., de la Rosa, J. M., Manning, D. A. C., Lopez-Capel, E., and Ding, L.: Comparison of black carbon quantification methods to measure fire-derived (black/elemental) carbon in soils and sediments using reference materials from soil, water, sediment and the atmosphere, Global Biogeochem. Cy., 21, GB3016, doi:10.1029/2006GB002914, 2007.

Han, Y., Cao, J., Chow, J. C., Watson, J. G., An, Z., Jin, Z., Fung, K., and Liu, S.: Evaluation of the thermal/optical reflectance method for discrimination between char- and soot-EC, Chemosphere, 69, 569-574, doi:10.1016/j.chemosphere.2007.03.024, 2007.

Heal, M. R., Naysmith, P., Cook, G. T., Xu, S., Duran, T. R., and Harrison, R. M.: Application of ${ }^{14} \mathrm{C}$ analyses to source apportionment of carbonaceous $\mathrm{PM}_{2.5}$ in the UK, Atmos. Environ., 45, 2341-2348, doi:10.1016/j.atmosenv.2011.02.029, 2011.

Hitzenberger, R., Dusek, U., and Berner, A.: Black carbon measurements using an integrating sphere, J. Geophys. Res., 101, 1960119606, doi:10.1029/95JD02412, 1996.

Ishiguro, T., Takatori, Y., and Akihama, K.: Microstructure of diesel soot particles probed by electron microscopy: First observation of inner core and outer shell, Combust. Flame, 108, 231-234, doi:10.1016/S0010-2180(96)00206-4, 1997.

Levin, I., Naegler, T., Kromer, B., Diehl, M., Francey, R. J., GomezPelaez, A. J., Steele, L. P., Wagenbach, D., Weller, R., and Worthy, D. E.: Observations and modelling of the global distribution and long-term trend of atmospheric ${ }^{14} \mathrm{CO}_{2}$, Tellus B, 62, 26-46, 2010.

Lewis, C. W., Klouda, G. A., and Ellenson, W. D.: Radiocarbon measurement of the biogenic contribution to summertime $\mathrm{PM}_{2.5}$ ambient aerosol in Nashville, TN, Atmos. Environ., 38, 60536061, 2004.

Minguillón, M. C., Perron, N., Querol, X., Szidat, S., Fahrni, S. M., Alastuey, A., Jimenez, J. L., Mohr, C., Ortega, A. M., Day, D. A., Lanz, V. A., Wacker, L., Reche, C., Cusack, M., Amato, F., Kiss, G., Hoffer, A., Decesari, S., Moretti, F., Hillamo, R., Teinilä, K., Seco, R., Peñuelas, J., Metzger, A., Schallhart, S., Müller, M., Hansel, A., Burkhart, J. F., Baltensperger, U., and Prévôt, A. S. H.: Fossil versus contemporary sources of fine elemental and organic carbonaceous particulate matter during the DAURE campaign in Northeast Spain, Atmos. Chem. Phys., 11, 12067-12084, doi:10.5194/acp-11-12067-2011, 2011.

Mohn, J., Szidat, S., Fellner, J., Rechberger, H., Quartier, R., Buchmann, B., and Emmenegger, L.: Determination of biogenic and fossil $\mathrm{CO}_{2}$ emitted by waste incineration based on $\left(\mathrm{CO}_{2}\right)$ C-14 and mass balances, Bioresour. Technol., 99, 6471-6479, doi:10.1016/j.biortech.2007.11.042, 2008.

Petzold, A., Ogren, J. A., Fiebig, M., Laj, P., Li, S.-M., Baltensperger, U., Holzer-Popp, T., Kinne, S., Pappalardo, G., Sugimoto, N., Wehrli, C., Wiedensohler, A., and Zhang, X.-Y.: Recommendations for reporting "black carbon" measurements, Atmos. Chem. Phys., 13, 8365-8379, doi:10.5194/acp-13-83652013, 2013.
Pöschl, U.: Atmospheric aerosols: Composition, transformation, climate and health effects, Angewandte Chemie, 44, 7520-7540, doi:10.1002/anie.200501122, 2005.

Prokopiou, M.: Characterization of a thermal method for separating organic and elemental carbon from aerosol samples using ${ }^{14} \mathrm{C}$ analysis, M.S. thesis, University of Groningen, the Netherlands, 2010.

Reimer, P., Brown, T., and Reimer, R.: Discussion: Reporting and calibration of post-bomb ${ }^{14} \mathrm{C}$ data, Radiocarbon 46, 1299-1304, 2004.

Schichtel, B. A., Malm, W. C., Bench, G., Fallon, S., McDade, C. E., Chow, J. C., and Watson, J. G.: Fossil and contemporary fine particulate carbon fractions at 12 rural and urban sites in the United States, J. Geophys. Res., 113, D02311, doi:10.1029/2007JD008605, 2008.

Sharma, H. N., Pahalagedara, L., Joshi, A., Suib, S. L., and Mhadeshwar, A. B.: Experimental Study of Carbon Black and Diesel Engine Soot Oxidation Kinetics Using Thermogravimetric Analysis, Energy Fuels, 26, 5613-5625, doi:10.1021/ef3009025, 2012.

Song, J., Huang, W., and Peng, P.: Stability and carbon isotope changes of soot and char materials during thermal oxidation: Implication for quantification and source appointment, Chem. Geol., 330, 159-164, doi:10.1016/j.chemgeo.2012.08.003, 2012.

Su, D. S., Jentoft, R. E., Müller, J., Rothe, D., Jacob, E., Simpson, C. D., Tomović, Ž., Müllen, K., Messerer, A., Pöschl, U., Niessner, R., and Schlögl, R.: Microstructure and oxidation behaviour of Euro IV diesel engine soot: a comparative study with synthetic model soot substances, Catal. Today, 90, 127-132, doi:10.1016/j.cattod.2004.04.017, 2004.

Szidat, S., Jenk, T. M., Gaggeler, H. W., Synal, H. A., Hajdas, I., Bonani, G. and Saurer, M.: THEODORE, a two-step heating system for the EC/OC determination of radiocarbon (C-14) in the environment, Nucl. Instrum. Meth. B, 223, 829-836, 2004.

Szidat, S., Jenk, T. M., Synal, H. A., Kalberer, M., Wacker, L., Hajdas, I., Kasper-Giebl, A., and Baltensperger, U.: Contributions of fossil fuel, biomass-burning, and biogenic emissions to carbonaceous aerosols in Zurich as traced by C-11, J. Geophys. Res., 111, D07206, doi:10.1029/2005JD006590, 2006.

Szidat, S., Prevot, A. S. H., Sandradewi, J., Alfarra, M. R., Synal, H. A., Wacker, L., and Baltensperger, U.: Dominant impact of residential wood burning on particulate matter in Alpine valleys during winter, Geophys. Res. Lett., 34, L05820, doi:10.1029/2006GL028325, 2007.

Szidat, S., Ruff, M., Perron, N., Wacker, L., Synal, H.-A., Hallquist, M., Shannigrahi, A. S., Yttri, K. E., Dye, C., and Simpson, D.: Fossil and non-fossil sources of organic carbon (OC) and elemental carbon (EC) in Göteborg, Sweden, Atmos. Chem. Phys., 9, 1521-1535, doi:10.5194/acp-9-1521-2009, 2009.

Szidat, S., Bench, G., Bernardoni, V., Calzolai, G., Czimczik, C. I., Derendorp, L., Dusek, U., Elder, K., Fedi, M., Genberg, J., Gustafsson, Ö., Kirillova, E., Kondo, M., McNichol, A. P., Perron, N., dos Santos, G. M., Stenström, K., Swietlicki, E., Uchida, M., Vecchi, R., Wacker, L., Zhang, Y., and Prévôt, A. S. H.: Intercomparison of ${ }^{14} \mathrm{C}$ Analysis of Carbonaceous Aerosols: Exercise 2009, Radiocarbon, 55, 1496-1509, 2013.

van der Plicht, J., Wijma, S., Aerts, A. T., Pertuisot, M. H., and Meijer, H. A. J.: Status report: The Groningen AMS facil- 
ity, Nucl. Instrum. Meth. B, 172, 58-65, doi:10.1016/S0168583X(00)00284-6, 2000.

Wonaschütz, A., Hitzenberger, R., Bauer, H., Pouresmaeil, P., Klatzer, B., Caseiro, A., and Puxbaum, H.: Application of the Integrating Sphere Method to Separate the Contributions of Brown and Black Carbon in Atmospheric Aerosols, Environ. Sci. Technol., 43, 1141-1146, doi:10.1021/es8008503, 2009.

Yezerets, A., Currier, N. W., Kim, D. H., Eadler, H. A., Epling, W. S., and Peden, C. H. F.: Differential kinetic analysis of diesel particulate matter (soot) oxidation by oxygen using a step-response technique, Appl. Catal. B-Environ., 61, 120-129, doi:10.1016/j.apcatb.2005.04.014, 2005.

Yu, J. Z., Xu, J. H., and Yang, H.: Charring characteristics of atmospheric organic particulate matter in thermal analysis, Environ. Sci. Technol., 36, 754-761, 2002.
Zencak, Z., Elmquist, M., and Gustafsson, O.: Quantification and radiocarbon source apportionment of black carbon in atmospheric aerosols using the CTO-375 method, Atmos. Environ. 41, 7895-7906, doi:10.1016/j.atmosenv.2007.06.006, 2007.

Zhang, Y. L., Perron, N., Ciobanu, V. G., Zotter, P., Minguillón, M. C., Wacker, L., Prévôt, A. S. H., Baltensperger, U., and Szidat, S.: On the isolation of OC and EC and the optimal strategy of radiocarbon-based source apportionment of carbonaceous aerosols, Atmos. Chem. Phys., 12, 10841-10856, doi:10.5194/acp-12-10841-2012, 2012. 